\title{
Shear bond strength of pit and fissure sealants on permanent teeth after several etching protocols: In vitro study
}

\section{Wytrzymałość na ścinanie laków szczelinowych w zębach stałych po zastosowaniu kilku protokołów wytrawiania - badania in vitro}

\author{
Irina Mézquita-Rodrigo ${ }^{B-D, F}$, Rosalía Contreras-Bulnes ${ }^{A-F}$, Laura Emma Rodríguez-Vilchis ${ }^{A-F}$, Rogelio José Scougall-Vilchis ${ }^{A, C, E, F}$, \\ Ulises Velazquez-Enriquez ${ }^{\mathrm{C}, \mathrm{E}, \mathrm{F}}$, Claudia Centeno-Pedraza ${ }^{\mathrm{B}, \mathrm{F}}$
}

Dental and Advanced Studies Research Center, Faculty of Dentistry Autonomous Unversity State of Mexico, Toluca, Mexico

A - research concept and design; B - collection and/or assembly of data; C - data analysis and interpretation;

$D$ - writing the article; $E$ - critical revision of the article; $F$ - final approval of article

Address for correspondence

Rosalía Contreras-Bulnes

E-mail: rcontrerasb@uaemex.mx

Funding sources

none declared

Conflict of interest

none declared

Acknowledgements

We thank to Dr. Miguel Angel Vázquez Rodríguez from the Center for Dental Specialties, Maternal and Child Institute of the State of Mexico and to Dr. Israel Ramírez López from the Dental Clinic Morelos, Institute of Social Security of the State of Mexico and Municipalities, for their assistance with obtaining the samples. This research was supported by Autonomous University State of Mexico.

Received on May 29, 2017

Revised on June 07,2017

Accepted on June 12, 2017

D0I

$10.17219 / \mathrm{dmp} / 75873$

Copyright

○ 2017 by Wroclaw Medical University

and Polish Dental Society

This is an article distributed under the terms of the

Creative Commons Attribution Non-Commercial License

(http://creativecommons.org/licenses/by-nc-nd/4.0/)

\begin{abstract}
Background. The pit and fissure areas are 8 times more vulnerable to caries; consequently, sealants have been proven to be efficient. Acid etching is the standard procedure for enamel etching; however, it leaves a demineralized surface. Laser Er:YAG is a good etching alternative due to its properties.

Objectives. The aim of this study was to evaluate the effect of different conditioning agents on shear bond strength (SBS) of sealants in permanent teeth.

Material and methods. A total of 156 third molar samples were divided into 6 groups ( $n=25$ each). Treated as follows: Gl acid etching (35\% phosphoric acid), Gll Er:YAG laser, GIII self-etching adhesive, GIV acid + Er:YAG laser, GV Er:YAG laser + acid and GVI Er:YAG laser + self-etching adhesive. Er:YAG laser irradiation was at $19.1 \mathrm{~J} / \mathrm{cm}^{2}$, water spraying at $5.0 \mathrm{~mL} / \mathrm{min}$. Sealant blocks were made and bonded on the enamel with a sealant in order to perform SBS test and adhesive remnant index (ARI). Samples were stored $\left(37^{\circ} \mathrm{C}, 24 \mathrm{~h}\right)$, tested, and statistically analyzed with a one way ANOVA, Kruskall-Wallis and Mann-Whitney U. SEM images were taken to assess the conditioning methods $(n=6)$.

Results. Er:YAG + self-etching group showed the lowest range. The highest values were observed in Gl, $\mathrm{GII}$ and GIII, no significant differences were found among them. The largest amount of adhesive remnant was found in group $V$.

Conclusions. Phosphoric acid (35\%), self-etching as well as 35\% phosphoric acid + Er:YAG laser protocols showed a better shear bond strength for pit and fissure sealant adhesion. Er:YAG laser + self-etching protocol is not recommended for this procedure, due to the lack of adequate adhesive strength.
\end{abstract}

Key words: shear bond strength, pit and fissure sealants, several etching protocols Słowa kluczowe: wytrzymałość na ścinanie, laki szczelinowe, techniki wytrawiania szkliwa 
Modern dentistry requires new prevention options to decrease the incidence of caries in both adults and children. Pit and fissure sealants are one of the best preventive methods against caries in susceptible teeth, mainly on occlusal surfaces. ${ }^{1}$

Nowadays, more effective techniques have been preferred, which are precise and minimally invasive, to prepare hard dental tissues. ${ }^{2}$ In order to improve the effectiveness of sealants, the use of Er:YAG may be beneficial due to its properties. Acid etching produces iatrogenic effects on the enamel surface, such as demineralization and irreversible loss of approximately $10 \mu \mathrm{m}$ and, therefore, the surface becomes susceptible to caries. ${ }^{3}$

Additionally, there have been several studies in which it has been observed that enamel structure is modified, increasing the resistance against caries, due to thermally induced chemical and structural changes in the intrinsic mineral and organic matrix, as well as reduction of carbonates. ${ }^{4-6}$

The aim of this in vitro study was to evaluate and compare shear bond strength of sealants prior to enamel conditioning under several etching protocols in permanent teeth.

\section{Material and methods}

\section{Tooth selection and sample preparation}

The protocol of this study was reviewed and approved by the Research Ethics Committee of Dental Research and Advances Studies Center, School of Dentistry, at the Autonomous University of the State of Mexico (Certificate of Ethical Approval: CEICIEAO-2016-003).

A total of 78 sound third molar teeth extracted surgically for therapeutic reasons, with an intact enamel surface and without any evidence of fracture, damage or caries, were obtained with the patients' informed consent. The teeth were extracted and collected, stored in a $0.2 \%$ (wt./vol) thymol solution at room temperature for a period no longer than 2 months.

The specimens were cleaned with deionized water, and any remaining soft tissue was removed with a scalpel. The crown of each tooth was separated using a diamond disc (BesQual, New York, USA) mounted on a low-speed motor (Micro motor M2 Master, M25800011, Drillco Devices Ltd., Miami, FL, USA) under deionized water irrigation to prevent dehydration. The crown was fixed to a glass slide with thermo plasticized epoxy resin (Allied High Tech Products, Rancho Dominguez, USA). Afterwards, a diamond wheel (South Bay Technology, Inc., San Clemente, USA) mounted on a cutter (South Bay Technology, Inc., USA) was used to obtain the samples under constant irrigation. Each tooth was cut to obtain 2 halves (mesio-distal). Finally, the samples were thoroughly washed with deionized water.
A total of 150 samples were used to evaluate the SBS $(\mathrm{n}=25)$, whereas 6 were used for SEM observations. The teeth were fixed in acrylic resin; the sample was ground on the center, using a diamond disc to flatten the enamel surface, in order to standardize the area. Teeth were pumiced with fluoride-free paste (Pressage, Shofu Inc, Kyoto, Japan) and rubber prophylactic cups, washed with deionized water, and dried with compressed air.

Samples were randomly assigned to one of the 6 groups of enamel conditioning protocols; diagram of experimental design is shown in Fig. 1.

\section{Surface treatments}

One hundred and fifty samples were randomly assigned to 6 groups $(n=25)$ as shown in Table 1 . Then, the enamel surface was conditioned as follows:

Group I: Acid etching with 35\% phosphoric acid etching gel (Scotchbond Universal ${ }^{\circledR}, 3 \mathrm{M}$ ESPE, St Paul, MN, USA). The acid gel was applied on the enamel for $15 \mathrm{~s}$, rinsed thoroughly with forceful air, deionized with water spray, and dried with compressed air.

Group II: Er:YAG laser. The irradiation of the specimens was performed using an Er:YAG laser system (OpusDuo AquaLite ${ }^{\circledR} \mathrm{EC}, \mathrm{Er}$ :YAG $+\mathrm{CO}_{2}$, Lumenis, Yokneam, Israel). The main experimental parameters of the laser utilized during the study were wavelength fixed at $2.94 \mu \mathrm{m}$, energy pulse from $150 \mathrm{~mJ}$, energy density $19.1 \mathrm{~J} / \mathrm{cm}^{2}$, pulse repetition rate of $10 \mathrm{~Hz}$, pulse duration of $400 \mu \mathrm{s}$, and an exit tip diameter of $1.0 \mathrm{~mm}$.

Energy levels were calibrated using the calipers of the equipment, and the energy delivered was measured periodically with a power meter. The surface was scanned once by hand for $15 \mathrm{~s}$, perpendicular to the enamel surface of the samples, at a working distance of $1 \mathrm{~mm}$ and deionized water spraying at $5.0 \mathrm{~mL} / \mathrm{min}$. After Er:YAG laser irradiation, samples were rinsed thoroughly with deionized water spray and dried with compressed air.

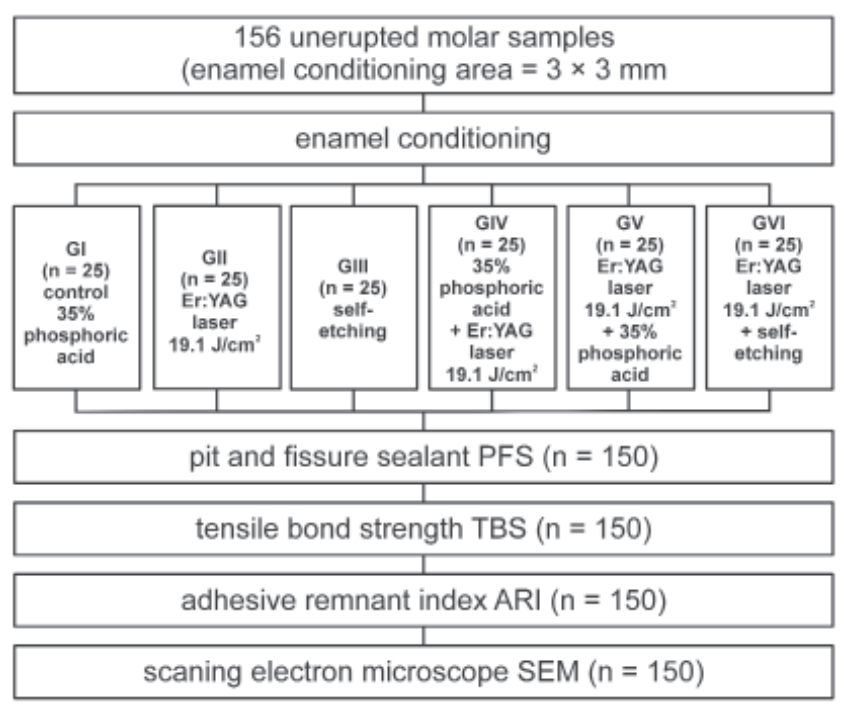

Fig. 1. Diagram of experimental design 
Table 1. Study groups

\begin{tabular}{|l|l|}
\hline Group & \multicolumn{1}{c|}{ Etching agents } \\
\hline GI & 35\% phosphoric acid \\
GII & Er:YAG laser \\
GIII & Self-etching adhesive \\
GIV & 35\% phosphoric acid + Er:YAG laser \\
GV & Er:YAG laser + 35\% phosphoric acid \\
GVI & Er:YAG laser + self-etching adhesive \\
\hline
\end{tabular}

Group III: Self-etching adhesive, with Adper Prompt L-Pop ${ }^{\circledR}$ (3M ESPE, St Paul, USA). It was activated according to the manufacturer's instructions. The resulting mix was then applied by continuously rubbing it the enamel surface for $15 \mathrm{~s}$, which was then slightly dried using compressed air for 1-2 s, and then light-cured with Ortholux Luminous Curing Light $^{\circledR}$ (3M Unitek) for a total of $20 \mathrm{~s}$.

Group IV: Phosphoric acid + Er:YAG laser with 35\% phosphoric acid etching gel (Scotchbond Universal, 3M ESPE, St Paul, USA) + Er:YAG laser, with the same irradiation parameters as used in group II.

Group V: Er:YAG laser + phosphoric acid, with the same parameters used in group II $+35 \%$ phosphoric acid etching gel (Scotchbond Universal, 3M ESPE, St Paul, USA).

Group VI: Er:YAG laser + self-etching adhesive, with the same parameters used in group II + self-etching adhesive Adper Prompt L-Pop (3M ESPE, St Paul, USA).

\section{Bonding procedure}

The specimens were prepared for the SBS test. To support this test, 150 sealant blocks (Clinpro ${ }^{\mathrm{TM}}$, 3M ESPE, St Paul, USA) $3 \times 2 \times 1.5 \mathrm{~mm}$ in size were built. Each block was polymerized $20 \mathrm{~s}$ with Ortholux Luminous Curing Light (3M Unitek). Finally, each block was bonded with a sealant to the treated enamel surface. It was light-cured by Ortholux Luminous Curing Light (3M Unitek) for a total of $20 \mathrm{~s}$.

\section{Shear bond strength (SBS)}

SBS test was performed with a crosshead speed of $0.5 \mathrm{~mm} / \mathrm{min}$ until fracture occurred. It was determined and expressed in megapascals $(\mathrm{MPa})$ for each specimen. This was accomplished using the flattened end of a steel rod attached to the crosshead of a universal testing machine (Autograph AGS-X, Shimazdu, Kyoto, Japan).

\section{Adhesive remnant index (ARI)}

Once sealant blocks had been debonded, the enamel surface of each tooth was examined with a stereoscope (Nikon, Tokyo, Japan) at a magnification of $\times 10$ to determine the amount of residual adhesive remaining on each tooth. To delimit the area to be evaluated, a $3 \times 2 \mathrm{~mm}$ window was cut in the center of a $9 \times 9 \mathrm{~mm}$ colored film tape, and marks every $1 \mathrm{~mm}$ were carried out around it. This template was placed on the debonded area. The modified ARI scores were recorded with the following scale: $0=$ no sealant left on the tooth, 1 = less than half of sealant left on the tooth, 2 = more than half of the sealant left on the tooth, and 3 = all the sealant left on the tooth.

\section{Scanning electron microscope (SEM)}

After surface treatment, 6 etched samples (without bonded sealant block) were dried at room temperature. All the samples were fixed to aluminum stubs with an adhesive carbon tape (SPI Supplies, USA). The analysis was performed using a scanning electron microscope (JEOL, JSM-6510LV, Japan) in the low vacuum at $10 \mathrm{~Pa}$ of chamber pressure, with electron acceleration voltage of $25 \mathrm{kV}$ and detecting backscattered electrons. Enamel surface morphology was observed at $\times 100, \times 500$ and $\times 1000$ magnification.

\section{Statistical analysis}

All the data was analyzed using the SPSS 21 statistical package (SPSS IBM, New York, NY, USA). The Kolmogorov-Smirnov test was performed to estimate the distribution of the data. The one way analysis of variance (ANOVA) was used to compare the shear bond strength in the groups; when significant differences were found, the Tamhane's T2 post-hoc tests were applied, due to Levene's test of homogeneity of variance showing different variances. Kruskall-Wallis and Mann-Whitney U tests were used to estimate the differences between ARI groups with a level of significance $\mathrm{p} \leq 0.05$ in the whole statistical analysis.

\section{Results}

The SBS, expressed in MPa, and descriptive statistics are shown in Table 2; Er:YAG + self-etching group showed the lowest range. The highest values were observed in group I, group II and group III, no significant differences were found among them. The ARI scores indicating the amount of adhesive remaining after debonding are shown in Table 3. Kruskall-Wallis and Mann-Whitney U tests comparison of the ARI scores indicated that group $\mathrm{V}$ was significantly different from all groups ( $\mathrm{p} \leq 0.05)$. The largest amount of adhesive remnant also was found in group V.

SEM analysis showed the different etching patterns obtained for each group (Fig. 2). After phosphoric acid treatment (Fig. 2a-c), a typical etching pattern was observed, mixed prism centers and prism periphery etching. For Er:YAG laser etching group (Fig. 2d-f) a rough surface with increased exposure along the prisms was observed, as well as microcracks. 
Table 2. Mean bond streght values (MPa) and descriptise statistics

\begin{tabular}{|c|c|c|c|c|c|}
\hline Group & $\mathrm{n}$ & Mean & SD & Range & * Tamhane's T2 \\
\hline I & 25 & 10.98 & 3.96 & $19.09-3.04$ & A \\
II & 25 & 7.99 & 2.04 & $12.18-3.81$ & B \\
III & 25 & 8.31 & 2.86 & $14.04-2.06$ & A, B \\
IV & 25 & 10.39 & 2.30 & $13.60-5.44$ & A \\
V & 25 & 7.72 & 2.48 & $12.47-2.05$ & B \\
VI & 25 & 4.56 & 1.74 & $11.05-2.90$ & C \\
\hline
\end{tabular}

* Groups with different letters are significantly different from each other; Tamhane's T2 post- hoc test, $\mathrm{p} \leq 0.05$.

Self-etching group (Fig. 2g-i) showed an etching pattern less pronounced, with an apparent lower loss of interprismatic substance.

For acid + Er:YAG laser group (2m, 2n and 2o), characteristics combination for groups I and II was observed. Er:YAG laser + phosphoric acid group showed a rough surface, microcracks and a mild etching pattern.

Findings for Er:YAG laser + self-etching group (2p, $2 \mathrm{q}$ and $2 \mathrm{r}$ ) exhibited minimal loss of interprismatic substance, when compared to group III.

\section{Discussion}

Because detecting caries ahead of time increases the possibility of minimizing the loss of dental tissue, by allowing remineralization and permitting the practitioner to take preventive or minimally invasive measures, ${ }^{2}$ different methods, technological innovations as well as the evolution of dental materials have been used for enamel surfaces conditioning prior to sealant placement in an attempt to increase adhesion. ${ }^{7}$

In the present study, several etching protocols were evaluated, conventional etching, self-etching adhesive, Er:YAG laser irradiation, as well as some combination procedures.

Although Ciucchi et al. indicates that pre-treatment with Er:YAG laser produces similar results as phosphoric acid on enamel surface as those observed in this research micrographs, SBS evaluation showed lower values for Er:YAG laser protocol alone compared to phosphoric acid, self-etching and phosphoric acid + Er:YAG groups. ${ }^{8}$

Ciucchi et al. ${ }^{8}$ and Yung et al. ${ }^{9}$ concluded that the combination of phosphoric acid + Er:YAG laser improved SBS and microfiltration, respectively. Additionally, Lupi-Pegúrier et al. assumed that if Er:YAG laser can effectively be used for the preparation of dental enamel before sealing pits and fissures, it must be associated with acid etching to provide a suitable surface, which is not conducive to microleakage. ${ }^{10}$ It was concluded that acid etch technique remains mandatory even after laser conditioning, for both enamel and dentin..$^{10,11}$

The adjunction of phosphoric acid etching to laser has not surpass simple acid etching, a finding corroborated in this and other studies outcomes. ${ }^{8,12,13}$ However, its use

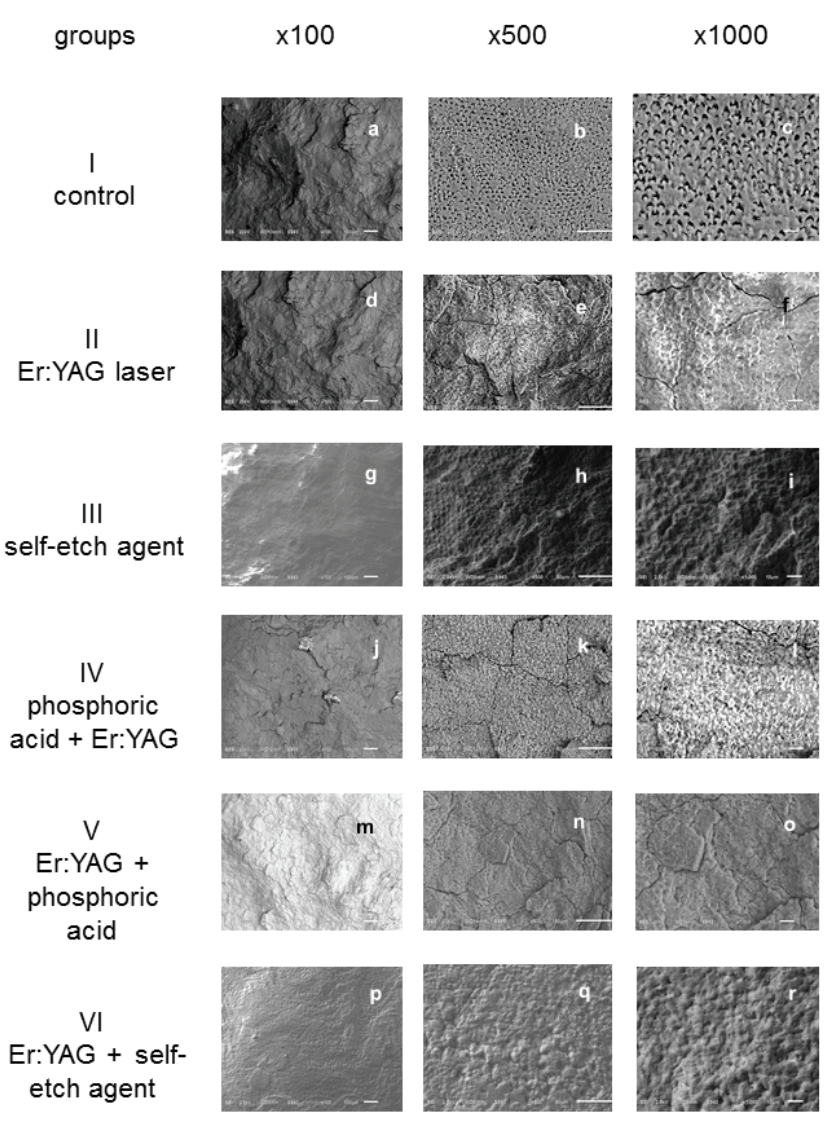

Fig. 2. Representative scanning electron microscopic (SEM) micrographs of enamel surfaces for each etching protocol

could be justified by the fact that several studies ${ }^{11,14,15}$ reported that enamel Er:YAG laser results in a suitable micro retentive pattern for adhesion and can increase enamel acid resistance, ${ }^{9,15-17}$ contrary to acid etching which demineralizes enamel surface leading to caries. ${ }^{15,18}$

Additionally, it is also thought to have an antibacterial effect by entrapping free ions ${ }^{12,18,19}$ and forming remineralization microspaces. ${ }^{12,19}$ Nevertheless, laser treatment requires specific considerations as the use of correct tip, ${ }^{8,15,20}$ adequate energy, otherwise could result in sub or over ablative energy, causing either flacking $8,18,21,22$ or vitrification. ${ }^{8,20}$ Furthermore, dental tissues response depends on several conditions such as focal distance, irriga-

Table 3. Distribution frequency and percentages of the adhesive remnant index (ARI)

\begin{tabular}{|c|c|c|c|c|c|c|}
\hline \multirow{2}{*}{ Group } & \multirow{2}{*}{$n$} & \multicolumn{4}{|c|}{ ARI Scores (\%) } & \multirow{2}{*}{$\begin{array}{l}\text { Statistic } \\
\text { analysis }\end{array}$} \\
\hline & & 0 & 1 & 2 & 3 & \\
\hline I & 25 & $17(68)$ & $5(20)$ & $3(12)$ & $0(0)$ & $A, B$ \\
\hline$\|$ & 25 & $19(76)$ & $6(24)$ & $0(0)$ & $0(0)$ & A \\
\hline III & 25 & $11(44)$ & $11(44)$ & $2(8)$ & $1(4)$ & $B$ \\
\hline IV & 25 & $18(72)$ & $6(24)$ & $1(4)$ & $0(0)$ & A \\
\hline V & 25 & $1(4)$ & $12(48)$ & $12(48)$ & $0(0)$ & C \\
\hline VI & 25 & $22(88)$ & $3(12)$ & $0(0)$ & $0(0)$ & $A$ \\
\hline
\end{tabular}

* Groups with different letters are significantly different from each other. Kruskall-Wallis and Mann-Whitney U tests, $\mathrm{p} \leq 0.05$. 
tion, among others; $;^{15,23}$ in addition, ablation process could lead to produce a microretentive surface on enamel. ${ }^{20,22}$

Regarding the self-etching adhesive employed in this study, it had similar SBS values to all the groups, except for group VI (in combination with previous Er:YAG laser irradiation). It has been reported that same self-etching adhesive resulted in SBS value comparable to that obtained for phosphoric acid, when they were employed for enamel etching previous to orthodontic brackets bonding. ${ }^{24}$ In addition, self-etching adhesive leaves fewer remnants, so it might be beneficial because the enamel is less damaged, ${ }^{24-26}$ as shown by SEM micrographs. An additional advantage of several self-adhesive systems are the antibacterial properties against Streptococcus mutans. ${ }^{27}$ Łukomska-Szymanska et al. reported that different selfetching bonding systems exhibited higher antimicrobial activity than some total-etching adhesives against Enterococcus faecalis. ${ }^{28}$ Specifically, Adper Prompt L-Pop exhibited the highest antibacterial effect among other $6^{\text {th }}$ generation bonding systems. ${ }^{29}$

Moreover, we observed that Er:YAG laser and self-etching adhesive combination was not adequate in improving SBS, in contrast to Yung, et al., who found that enamel laser conditioning did not significantly change the bond strength of the $4^{\text {th }}, 6^{\text {th }}$ and $7^{\text {th }}$ generations of bonding systems. ${ }^{9}$ Additionally, Chen et al. reported that Er:YAG laser conditioning may not compromise self-etching adhesives efficacy when employed for dentin conditioning. ${ }^{30}$

Based on the evaluation of all outcome parameters defined in this in vitro study, the etching protocols could be grouped into 4 categories according to SBS values and statistical analysis. Optimal adhesion includes phosphoric acid and phosphoric acid + Er:YAG laser groups, followed by appropriate adhesion for self-etching group, sufficient adhesion for Er:YAG laser and Er:YAG laser + phosphoric acid groups. Finally, there was insufficient adhesion for Er:YAG + self-etching group.

It is suggested that decisions of clinical use for the optimal, appropriate and sufficient categories would be based on the specific conditions of each patient, as well as the available resources. However, considering that in vitro conditions have limitations, it is worth conducting further research to evaluate the in vivo effects of enamel conditioning on sealant retention.

\section{Conclusions}

The results of this study suggest that the most appropriate enamel etching protocols for pit and fissure sealants adhesion on permanent teeth were phosphoric acid etching per se or in combination with Er:YAG laser irradiation (after acid etching). Er:YAG laser + self-etching protocol is not recommended, because bonding value is not clinically acceptable.

The authors declare that there is no conflict of interests regarding the publication of this paper.

\section{References}

1. Ahovuo-Saloranta A, Forss $H$, Walsh $T$, et al. Sealants for preventing dental decay in the permanent teeth. Cochrane Database Syst Rev. 2013;28:1-32.

2. Perhavec T, Gorkič A, Bračun D, Diaci J. A method for rapid measurement of laser ablation rate of hard dental tissue. Opt Laser Technol. 2009;41:397-402.

3. Cartensen W. The effects of different phosphoric acid concentrations on surface enamel. Angle Orthod. 1992;62:51-58.

4. Oho T, Morioka T. A possible mechanism of acquired acid resistance of human dental enamel by laser irradiation. Caries Res. 1990;24:86-92.

5. Fried D, Featherstone JDB, Visuri SR, Seka W, Walsh JT. The caries inhibition potential of Er:YAG and Er:YSGG laser radiation. Lasers in Dentistry II. Proceedings of SPIE, 1996; 2672:73-78.

6. Liu YY, Hsu CYS. Laser-induced compositional changes on enamel: A FT-Raman study. J Dent. 2007;35:226-230.

7. Borsatto MC, Corona SA, Dibb RG, Ramos RP, Pécora JD. Microleakage of a resin sealant after acid-etching, Er:YAG laser irradiation and air-abrasion of pits and fissures. J Clin Laser Med Surg. 2001;19:83-87.

8. Ciucchi, P, Neuhaus KW, Emerich M, Peutzfeldt A, Lussi A. Evaluation of different types of enamel conditioning before application of a fissure sealant. Lasers Med Sci. 2015;30:1-9.

9. Yung F, Gutknecht N, Franzen R, Fischer H. Shear strength of composite bonded to Er:YAG laser-prepared enamel: An in vitro comparative study. Lasers Med Sci. 2013;28:879-889.

10. Lupi-Pégurier L, Bertrand MF, Genovese O, Rocca JP, Muller-Bolla M. Microleakage of resin-based sealants after Er:YAG laser conditioning. Lasers Med Sci. 2007;22:183-188.

11. Lopes RM, Trevelin LT, da Cunha SR, et al. Dental adhesion to erbium-lased tooth structure: A review of the literature. Photomed Laser Surg. 2015;33:393-403.

12. Shahabi S, Bagheri HG, Ramazini K. Tensile bond strength of sealants following Er:YAG laser etching compared to acid etching in permanent teeth. Lasers Med Sci. 2012;27:371-375.

13. Bader C, Krejci I. Indications and limitations of Er:YAG laser applications in dentistry. Am J Dent. 2006;19:178-186.

14. Esteves-Oliveira M, Zezell DM, Apel C, et al. Bond strength of selfetching primer to bur cut, Er, Cr: YSGG, and Er:YAG lased dental surfaces. Photomed Laser Surg. 2007;25:373-380.

15. Chimello-Sousa DT, de Souza AE, Chinelatti MA, Pécora JD, Palma-Dibb RG, Milori Corona SA. Influence of Er:YAG laser irradiation distance on the bond strength of a restorative system to enamel. J Dent. 2006;34:245-251.

16. Colucci V, de Souza Gabriel AE, Scatolin RS, Serra MC, Corona SA. Effect of Er:YAG laser on enamel demineralization around restorations. Lasers Med Sci. 2015;30:1175-1181.

17. Díaz-Monroy JM, Contreras-Bulnes R, Olea-Mejía OF, Rodríguez-Vilchis LE, Sánchez-Flores I. Morphological changes produced by acid dissolution in Er: YAG laser irradiated dental enamel. Microsc Res Tech. 2014;77:410-414.

18. Kim JH, Kwon OW, Kim HI, Kwon YH. Acid resistance of erbiumdoped yttrium aluminum garnet laser-treated and phosphoric acid-etched enamels. Angle Orthod. 2006;76:1052-1056.

19. Mathew A, Reddy NV, Sugumaran DK, Peter J, Shameer M, Dauravu $\mathrm{LM}$. Acquired acid resistance of human enamel treated with laser (Er:YAG laser and $\mathrm{CO}_{2}$ laser) and acidulated phosphate fluoride treatment: An in vitro atomic emission spectrometry analysis. Contemp Clin Dent. 2013;4:170-175.

20. Güçlü ZA, Dönmez N, Tüzüner T, Odabaş ME, Hurt AP, Coleman NJ. The impact of Er:YAG laser enamel conditioning on the microleakage of a new hydrophilic sealant-UltraSeal $\mathrm{XT}^{\circledR}{ }^{\circledR}$ hydro ${ }^{\mathrm{TM}}$. Lasers Med Sci. 2016;31:705-711.

21. Alcántara-Galeana $M$, Contreras-Bulnes $R$, Rodríguez-Vilchis $L$, et al. Microhardness, structure, and morphology of primary enamel after phosphoric acid, self-etching adhesive, and Er:YAG laser etching. Int J Optics, 2017;ID7634739.

22. Wanderley RL, Monghini EM, Pecora JD, Palma-Dibb RG, Borsatto MC. Shear bond strength to enamel of primary teeth irradiated with varying Er:YAG laser energies and SEM examination of the surface morphology: An in vitro study. Photomed Laser Surg. 2005;23:260-267. 
23. Correa-Alfonso AM,Ciconne-NogueiraJC,PécoraJD,Palma-DibbRG. In vitro assessment of laser efficiency for caries prevention in pits and fissures. Microsc Res Tech. 2012;75: 245-252.

24. Contreras-Bulnes R, Scougall-Vilchis RJ, Rodríguez-Vilchis LE, Centeno-Pedraza C, Olea-Mejía OF, Alcántara-Galeana Mdel C Z. Evaluation of self-etching adhesive and Er:YAG laser conditioning on the shear bond strength of orthodontic brackets. SciWorldJ. 2013;ID719182.

25. Vicente A, Bravo LA, Romero M. Influence of a nonrinse conditioner on the bond strength of brackets bonded with a resin adhesive system. Angle Orthod. 2005;75:400-405.

26. Tecco S, Traini T, Caputi S, Festa F, de Luca V, D'Attilio M. A new one-step dental flowable composite for orthodontic use: An in vitro bond strength study. Angle Orthod. 2005;75:672-677.

27. Penmetsa RKR, Sri Rekha A, Poppuri KC, Sai Prashanth P, Garapati S. An in vitro evaluation of antibacterial properties of self etching dental adhesive systems. J Clin Diagn Res. 2014;8:1-5.

28. Łukomska-Szymanska M, Konieczka M, Zarzycka B, Lapinska B, Grzegorczyk J, Sokolowski J. Antibacterial activity of commercial dentine bonding systems against $E$. faecalis - flow cytometry study. Materials, 2017;10:481.

29. Łukomska-Szymanska M, Olbert-Sieroszewska V, Zurawska-Olszewska J, Szczerba I, Krzeminski Z, Sokołowski J. Antibacterial properties of $6^{\text {th }}$ generation bonding systems. Dent Med Probl. 2010;47:304-308 [in Polish].

30. Chen ML, Ding JF, He YJ, Chen Y, Jiang QZ. Effect of pretreatment on Er:YAG laser-irradiated dentin. Lasers Med Sci. 2015;30:753-759. 